
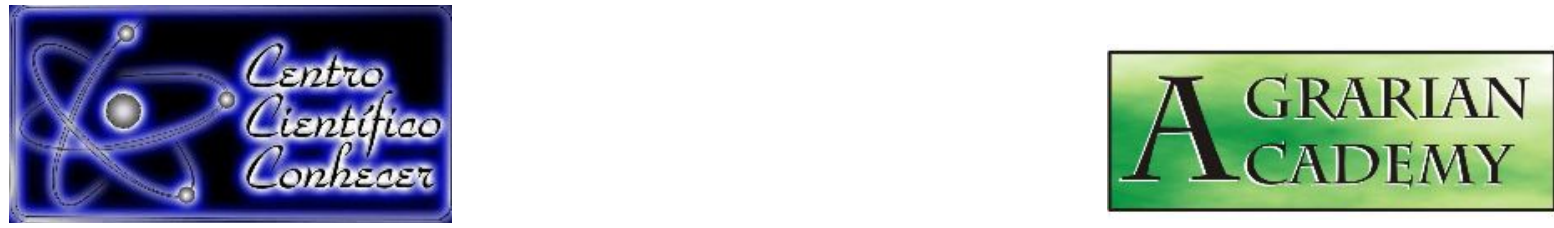

\title{
USO SUSTENTÁVEL DA BIODIVERSIDADE DO CERRADO NO MUNICÍPIO DE ITUIUTABA, MG
}

\author{
Thais Ramos da Silva', Priscila Alves Lima² \\ ${ }^{1}$ UEG - Universidade Estadual de Goiás, Unidade Universitária de Itumbiara, Goiás, \\ Brasil, trs_biologia@hotmail.com \\ ${ }^{2}$ UEG - Universidade Estadual de Goiás, Unidade Universitária de Ipameri, Goiás, \\ Brasil \\ Recebido em: 15/12/2021 - Aprovado em: 15/12/2021 - Publicado em: 30/12/2021 \\ DOI: 10.18677/Agrarian_Academy_2021B8 \\ trabalho licenciado sob licença Creative Commons Attribution-NonCommercial-NoDerivatives 4.0 International License.
}

\begin{abstract}
RESUMO
O objetivo do presente estudo foi contribuir com o desenvolvimento socioeconômico de agricultores familiares por meio da transferência de tecnologias para uso sustentável e comercialização da biodiversidade do Cerrado. O estudo foi executado no período de julho a novembro de 2019, com a comunidade de agricultores familiares da região de Ituiutaba, MG. Na primeira etapa do projeto foram colhidos dados sobre a realidade de produção dos agricultores familiares de Ituiutaba e elaboradas medidas intervencionistas, ou seja, oficinas, sendo: Boas práticas de higiene e esterilização no processamento de produtos agropecuários; O que é preciso para obter um registro no S.I.M.?; Processamento de queijos e iogurtes; Processamento de licores artesanais pela agricultura familiar; Agroecologia: conceitos e princípios; e, Manejos agroecológicos. As oficinas possibilitaram o atendimento de 50 pessoas, sendo agricultores familiares, alunos e comunidade da UEMG, Unidade de Ituiutaba. Após as oficinas, a maioria dos participantes declararam desejar utilizar os conhecimentos adquiridos para produzir novos produtos ou agregar valor aos seus produtos. Enfim, a comunidade de agricultores familiares de Ituiutaba, MG, demonstra boa aceitabilidade aos novos produtos.
\end{abstract}

PALAVRAS-CHAVE: agricultura familiar, desenvolvimento rural, extensão rural

\section{SUSTAINABLE USE OF THE CERRADO BIODIVERSITY IN ITUIUTABA, MG}

\begin{abstract}
The aim of this study was to contribute to the socioeconomic development of family farmers through the transfer of technologies for sustainable use and commercialization of Cerrado biodiversity. The study was carried out from July to November 2019, with the family farmers community of Ituiutaba region, MG. In the first stage of the project, data were collected on the reality of production of family farmers in Ituiutaba and interventionist measures were elaborated workshops: Good hygiene and sterilization practices in the processing of agricultural products; What does it take to get a S.I.M registration? Cheese and yogurt processing; Processing of handmade liqueurs by family farming; Agroecology: concepts and principles; and Agroecological management. The workshops allowed the attendance of 50 people,
\end{abstract}


being family farmers, students and the community of UEMG, Ituiutaba. After the workshops, most participants stated that they wanted to use their knowledge to produce new products or add value to their products. Finally, the community of family farmers in Ituiutaba, MG, demonstrated good acceptability to new products.

KEYWORDS: family farming, rural development, rural extension

\section{INTRODUÇÃO}

O município de Ituiutaba apresenta uma área de 2.598,046 km² (IBGE, 2018), dentro do Bioma Cerrado. A área rural é representada por 2500 produtores rurais, sendo destes 1150 agricultores familiares (EMATER, 2017). As atividades desenvolvidas pelos agricultores familiares são principalmente a pecuária de corte e leite e algumas poucas atividades extrativistas, como a exploração de frutos típicos do Cerrado.

A atividade pecuarista no Cerrado tem um modelo extremamente predatório, que ameaça a própria existência do Bioma, portanto, o modelo é insustentável no longo prazo, devido a seus sérios impactos socioambientais negativos (ABRAMOVAY, 2010). Além disso, a atividade pecuarista vem perdendo força e os agricultores familiares migrando para a cidade, devido à expansão das atividades sucroalcooleiras na região (FONSECA; SANTOS, 2011; OLIVEIRA, 2014). A baixa renda agropecuária obtida com os produtos comercializados é com certeza o motivo pelo qual os agricultores familiares abandonam suas terras e tentam uma melhor condição na área urbana (OLIVEIRA, 2014).

A melhoria das condições socioeconômicas, é considerada uma das mais eficientes alternativas de desenvolvimento rural do País (FIGUEIREDO; FIGUÊIREDO, 2010). Ainda de acordo com estes autores tal melhoria poderia ser realizada por meio do beneficiamento e/ou transformação dos produtos de explorações agrícolas, pecuária, extrativista e florestal. Estes processos são simples, como secagem, classificação, limpeza e embalagem, até processos mais complexos que incluem operações físicas, químicas ou biológicas, como, por exemplo, a extração de óleos, a caramelização e a fermentação.

Associada a estas técnicas a agroecologia agrega valor aos produtos. A agricultura que visa a saúde e o bem-estar das pessoas; produz alimentos de qualidade, com saúde e bem-estar das plantas e animais; gera autonomia para os agricultores e promove a justiça social e uma economia solidária (SILVA et al., 2014). o objetivo do projeto no modelo extensionista foi contribuir com o desenvolvimento socioeconômico de agricultores familiares por meio da transferência de tecnologias para uso sustentável e comercialização da biodiversidade do Cerrado.

\section{MATERIAL E MÉTODOS}

O estudo foi executado no período de julho a novembro de 2019, em Ituiutaba, MG, com a comunidade de agricultores familiares da região. A vegetação natural do local caracteriza-se pelo Cerrado principalmente com fisionomias mais abertas, devido a forte antropização ocorrida no local. São poucas as propriedades que se pode observar um estado mais conservado da vegetação, mesmo assim, observam-se várias espécies de interesse econômico como o pequi, caju e tamarindo.

$\mathrm{Na}$ primeira etapa do projeto foram colhidos dados sobre a realidade de produção dos agricultores familiares de Ituiutaba, MG. Os dados foram obtidos pela observação e diagnóstico através de uma interação verbal com os agricultores. 
Assim, foram elaboradas as medidas intervencionistas de acordo com a demanda das famílias, ou seja, foram realizadas oficinas com duração média de duas horas, uma vez por semana. As oficinas realizadas foram: Boas práticas de higiene e esterilização no processamento de produtos agropecuários; $\mathrm{O}$ que é preciso para obter um registro no S.I.M.?; Processamento de queijos e iogurtes; Processamento de licores artesanais pela agricultura familiar; Agroecologia - conceitos e princípios; e, Manejos agroecológicos.

Foram ministradas oficinas com o intuito de demonstrar os produtos agropecuários com potenciais de uso, bem como, capacitá-los na elaboração de produtos a partir da vegetação do Cerrado. As oficinas foram realizadas na Unidade de Ituiutaba da UEMG (Universidade Estadual de Minas Gerais), e foram envolvidos todos do processo de produção da agricultura familiar do município de Ituiutaba.

$\mathrm{Na}$ primeira oficina: Boas práticas de higiene e esterilização no processamento de produtos agropecuários, o professor da UEMG, Unidade de Ituiutaba, Ubiramar Ribeiro Cavalcante fez uma apresentação teórica de todos os cuidados que devem ser tomados na produção de alimentos: cuidados pessoais, com o ambiente/local, com os utensílios e com todo o processo de produção à entrega ao cliente. Após a explanação teórica o professor levou os alunos à cozinha comunitária da UEMG, onde foram demonstradas boas práticas ao manusear alimentos, como a higienização pessoal; utilização de touca, luvas e máscaras; e ainda, a produção de compotas.

A segunda oficina foi ministrada pela médica veterinária Gislaine de Fátima Carvalho, O que é preciso para obter um registro no S.I.M.?. A médica veterinária é a responsável pela emissão do certificado S.I.M. (Serviço de Inspeção Municipal) no município de Ituiutaba, MG. Sendo assim, ela explicou os passos para conseguir o registro. A instrutora explicou que o órgão S.I.M. emite o certificado que autoriza o produtor a comercializar seus produtos de origem animal no comércio local, e ainda, é responsável pela inspeção e fiscalização da produção industrial e sanitária dos produtos de origem animal, comestíveis e não comestíveis.

A oficina Processamento de queijos e iogurtes foi ministrada pelo Técnico de Laboratórios de Alimentos do IFTM (Instituto Federal do Triângulo Mineiro), Câmpus Ituiutaba, Vítor Hugo Pacheco Jardim. Na oficina, o técnico mostrou o passo a passo para a produção de iogurtes e queijo minas frescal. Inicialmente, o processo de fermentação e depois a saborização do iogurte a partir do leite já pasteurizado. Para a produção do queijo, foi feito o aquecimento do leite pasteurizado e coagulação. Depois do descanso do leite em processo de coagulação, foi prensado, salgado e colocado em formas próprias para o processo.

O aluno de graduação em Agronomia da UEMG, Josef Gastl Filho, ministrou a palestra Processamento de licores artesanais pela agricultura familiar. A oficina foi ministrada de forma prática e os participantes tiveram a oportunidade de produzir os licores de amora, caju e tamarindo. Primeiro, o palestrante mostrou o processo de esterilização e preparação das frutas utilizadas na preparação dos licores. Depois, a produção da calda de açúcar que é utilizada e, por fim, as medidas e o processo de produção para cada um dos licores descritos acima.

A quinta oficina, Agroecologia: conceitos e princípios, foi ministrada pela professora da UEMG, Amanda Fialho. A professora iniciou a oficina apresentando um histórico da agricultura, onde inicialmente se realizava uma agricultura orgânica e com o passar dos anos, a revolução agrícola trouxe a agricultura convencional. Segundo a professora, a agricultura verde, trouxe sustentabilidade aos processos de produção agrícola, sendo a solução apresentada para um esgotamento agrícola. $\mathrm{Na}$ 
oficina, foi apresentada a agroecologia como possível forma de realizar os cultivos, necessários para a sobrevivência humana, com a ideia de preservação dos ecossistemas, como o Cerrado.

A oficina Manejos Agroecológicos foi ministrada pela professora Priscila Alves Lima da UEMG. A oficina iniciou-se com uma explanação sobre o que seriam os manejos agroecológicos. Após esta explicação a professora mostrou aos participantes como produzir diversas caldas que podem ser utilizadas nos manejos agroecológicos no controle de pragas e doenças. Ainda demonstrou como pode ser realizada a aplicação destas caldas nas plantas.

Ao final de cada oficina foi realizada uma avaliação da oficina por meio de um diálogo com os ouvintes. O diálogo tinha o objetivo de promover uma auto avaliação das oficinas, também, avaliar se objetivo do projeto foi atingido, ou seja, verificar se as demandas e expectativas dos agricultores familiares de Ituiutaba, MG, foram atendidas.

\section{RESULTADOS E DISCUSSÃO}

As oficinas possibilitaram 0 atendimento de 50 pessoas. Dentre essas pessoas agricultores familiares, alunos e comunidade da UEMG, Unidade de Ituiutaba. Consideram-se, estes participantes, como multiplicadores, pois uma vez treinados, estes têm, em acordo firmado com a universidade, o dever de transferir a tecnologia para os demais agricultores familiares. Primeiramente, apresentaram as informações mais relevantes sobre os resultados obtidos com os diálogos com os agricultores familiares de Ituiutaba, MG.

As entrevistas desempenharam um papel muito importante, pois, permitiram o diagnóstico dos atores sociais e da realidade dos agricultores familiares, favorecendo o processo de autogerenciamento do planejamento para o projeto executado. Os agricultores familiares afirmaram não utilizar mão de obra externa à propriedade, apenas os residentes na propriedade com vínculo familiar. As propriedades são pequenas, assentados da reforma agrária. Também, com a pequena produção, não necessitam constantemente de equipamentos agrícolas.

A principal atividade econômica dos agricultores familiares de Ituiutaba é a pecuária leiteira. Os pecuaristas destinam a produção para os laticínios da região. Somente uma pequena parte dos produtores agrega valor ao leite produzindo doces e queijos para a comercialização em feiras do município de Ituiutaba, MG.

Este fato é explicado por Souto e Bezzi (2018), segundo os autores o município de Ituiutaba é o maior produtor leiteiro da MRG - 017 (microrregião geográfica de Ituiutaba- MG). Também, nesta unidade territorial, houve a instalação da processadora de leite Nestlé, no ano de 1974, ocasionando a expansão da quantidade produzida de leite bovino em 621,4\% entre 1974 a 2016 (IBGE, 2016). Além da Nestlé, existem duas agroindústrias leiteiras instaladas, as quais possuem capital de origem local, que são: A Fazendeira, fundada em 1938 e a Canto de Minas, que iniciou suas atividades em 1994.

Quanto às orientações recebidas, os agricultores familiares, afirmaram serem poucas, como da Emater, Sindicato dos Trabalhadores Rurais e Secretaria de Agricultura e Pecuária de Ituiutaba. Também, recebem apoio de profissionais dos laticínios, com os quais possuem vínculo em forma de cooperativa. Além disso, os agricultores familiares demonstraram desconhecimento a respeito das possibilidades de produção diversificada. Juntos, conhecimentos e diversificação produtiva constituem-se como aspectos centrais para as iniciativas de agregação de valor (OLIVEIRA et al., 2011). 
Os agricultores familiares, segundo Oliveira et al. (2011), possuem um papel ativo nos processos de produção e de reprodução por meio do conhecimento que acumularam e das decisões que tomam. Os agricultores podem negociar sua inserção nos mercados, tendo por base não somente o contexto em que operam, mas, também, os seus interesses e condições sociais. Para entender esta relação, os agricultores foram questionados se gostariam de ter outros produtos para comercializar. Assim, 50\% dos entrevistados afirmaram não ter interesse, mas, 50\% gostariam de aproveitar os recursos disponíveis para expandir os negócios e obter outras fontes de renda.

A primeira oficina oferecida foi a de Boas práticas de higiene e esterilização no processamento de produtos agropecuários. Os participantes conheceram a importância da higienização na manipulação dos alimentos, além dos procedimentos cruciais a serem tomados para garantir a qualidade dos produtos no beneficiamento de queijos, doces, compotas, entre outros.

A questão da qualidade do alimento agrega valor ao produto uma vez que o consumidor está cada vez mais exigente e conhecedor da segurança alimentar. Ainda, segundo Pinheiro et al. (2011), a qualidade, em geral, e os atributos de segurança do alimento são importantes elementos para a tomada de decisão dos consumidores. Dentre os mecanismos que podem contribuir para a percepção da qualidade do produto por parte dos consumidores, tem-se a imagem positiva da marca e a reputação da empresa, reconhecidas como estratégias de adição de valor ao produto.

Segundo Figueiredo e Figuêiredo (2010), a produção de alimentos com segurança exige cuidados especiais, para que se eliminem, quase na totalidade, os riscos de contaminação por perigos físicos, químicos e biológicos a que estes alimentos estão sujeitos. De acordo com Germano e Germano (2003), a segurança e a qualidade dos alimentos são fatores essenciais para a saúde pública, portanto, constitui um dever de todas as indústrias alimentícias a produção de alimentos inócuos e aptos para o consumo.

A segunda oficina ministrada abordou o que é preciso para obter um registro no S.I.M. A instrutora explicou os passos para conseguir o registro, informou que o órgão S.I.M. emite o certificado que autoriza o produtor a comercializar seus produtos de origem animal no comércio local, e ainda, que é responsável pela inspeção e fiscalização da produção industrial e sanitária dos produtos de origem animal, comestíveis e não comestíveis.

A importância do S.I.M. na agregação de valor aos produtos pode ser entendida a partir do que explica Pereira et al. (2018), segundo os autores o S.I.M. certifica através de selo, aqueles produtos que foram elaborados com a devida qualidade higiênica e sanitária. Os estabelecimentos com registro no S.I.M. podem comercializar os produtos apenas no território do município (PEREIRA et al., 2018).

A realidade da inspeção sanitária e da adequação dos produtos da agricultura familiar, principalmente os de origem animal, apresenta dificuldades que vão desde a limitação de ação dos serviços de inspeção, dadas a estrutura requerida aos municípios, até a adequação dos estabelecimentos de pequena escala, pois a legislação sanitária ainda é majoritariamente adaptada à estrutura agroindustrial de produção, independente da escala (PEREIRA et al., 2018).

$\mathrm{Na}$ oficina Processamento de queijos e iogurtes, foi mostrado o passo a passo para a produção de iogurtes e queijo minas frescal. Inicialmente, o processo de fermentação e depois a saborização do iogurte à partir do leite já pasteurizado. Para a produção do queijo, foi feito o aquecimento do leite pasteurizado e coagulação. 
Depois do descanso do leite em processo de coagulação, foi prensado, salgado e colocado em formas próprias para o processo (Figuras 1 e 2).

A produção de queijos e iogurtes é vista como uma atividade agroindustrial e conforme já foi discutido acima, a atividade agroindustrial é uma das principais fontes de agregação de valor aos produtos da agricultura familiar, aumentando a geração de renda e o fortalecimento das famílias produtoras e dos empreendedores no campo e na cidade (PEREIRA et al., 2018).

A agregação de valor ao leite pode contribuir para o desenvolvimento da produção e gerar renda na agricultura familiar do município, oferecendo para as crianças, através da merenda escolar e para as famílias produtoras, uma opção de geração de trabalho, renda e fixação do homem no campo.

Com uma matéria prima de boa qualidade é possível investir na criação de produtos mais elaborados e com maior valor agregado (queijos finos e iogurte com frutas). Desta forma, as indústrias dos agricultores familiares podem entrar no mercado sem competir diretamente com as grandes redes de laticínio. Isto exige novas formas de relacionamento com os consumidores, como a venda e a comunicação direta (CIRIACO, 2016).

FIGURA 1. Passo a passo do processo de produção do queijo minas frescal, ministrado pelo professor Vítor Hugo Pacheco Jardim.

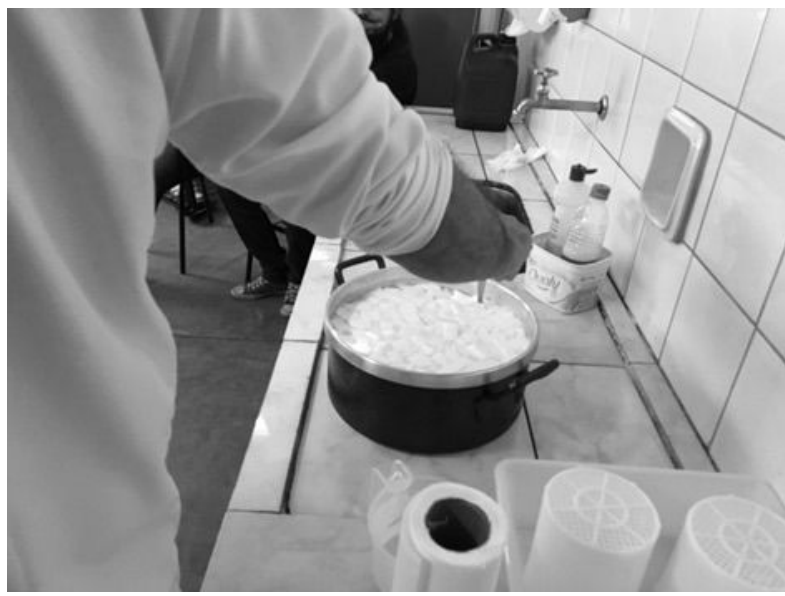

Fonte: As autoras, (2019).
FIGURA 2. Processo de produção de iogurte, ministrado pelo professor Vítor Hugo Pacheco Jardim.

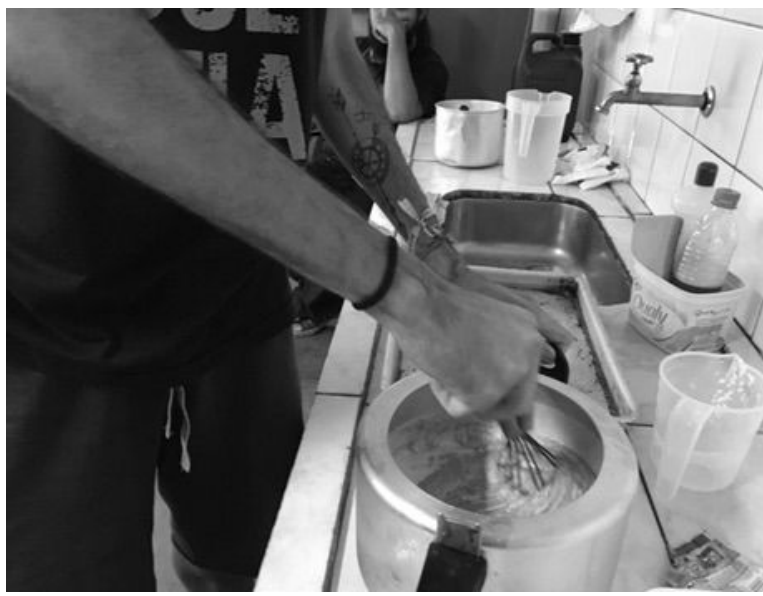

Fonte: As autoras, (2019).

O aluno Josef ministrou a palestra Processamento de licores artesanais pela agricultura familiar. A oficina foi ministrada de forma prática e os participantes tiveram a oportunidade de produzir os licores de amora, caju e tamarindo (Figura 3). Primeiro, o ministrante mostrou o processo de esterilização e preparação das frutas utilizadas na preparação dos licores. Depois, a produção da calda de açúcar, que é a calda utilizada para adoçar o licor. Por fim, foram realizadas as medidas para o processamento de cada um dos licores descritos acima.

Os frutos do Cerrado provenientes de floresta da reserva legal para o mercado podem ser utilizados de forma extrativista na agricultura familiar. Para agregação de valor a estes frutos, pode-se recorrer ao uso de tecnologias, como a produção de licores artesanais. 
FIGURA 3. Processamento dos licores de caju, amora e tamarindo na oficina ministrada pelo Josef Gastl Filho da UEMG, Unidade de Ituiutaba, MG.

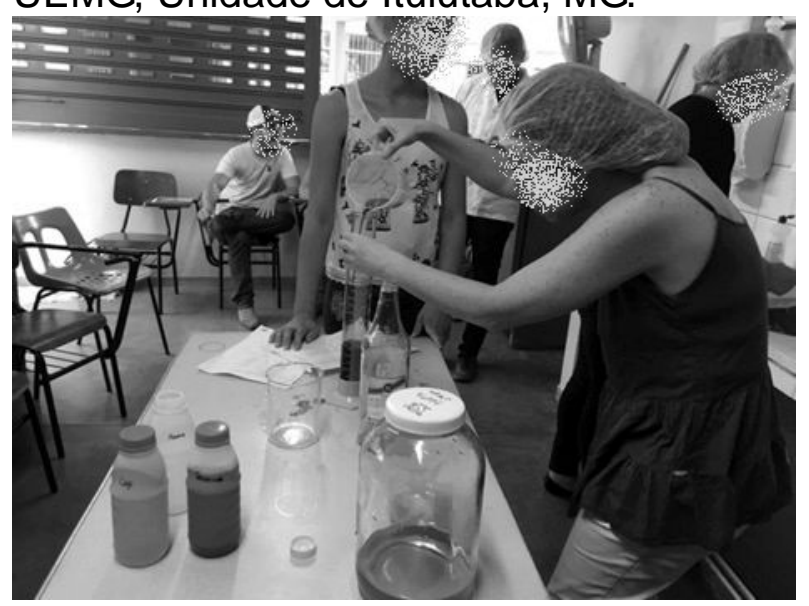

Fonte: As autoras, (2019).

Neste contexto, ações como estas, podem ainda, contribuir para conservar as áreas remanescentes de Cerrado. $\mathrm{O}$ uso de produtos florestais não madeireiros advindos da biodiversidade vegetal nativa, pode diminuir a pressão para o desmatamento de áreas naturais e, ao mesmo tempo, gerar renda aos agricultores familiares. Diversas espécies de plantas nativas do Cerrado apresentam importância biológica, social e econômica, reconhecidas tanto pelas comunidades tradicionais quanto pelas instituições de pesquisa (SOUSA; SANTOS, 2015). À medida que os produtos advindos da biodiversidade passam a gerar renda, eles são mais valorizados, contribuindo para a conservação (CARVALHO, 2007).

$\mathrm{Na}$ oficina Agroecologia - conceitos e princípios foi exposto pela palestrante a origem da agroecologia e, assim, as normas que regem os manejos agroecológicos. Através da oficina foi possível entender como realizar a agricultura sustentável aliada ao desenvolvimento rural.

Segundo Assis e Romeiro (2005), a agroecologia se apresenta no Brasil como uma forma de resistência contra a devastadora onda modernizadora e contra a expropriação completa dos agricultores. O que integra propostas agroecológicas com outras voltadas a desenvolver a agricultura familiar.

A professora Priscila mostrou aos participantes como produzir caldas a partir de produtos caseiros que podem ser utilizados no controle de pragas e doenças para a agroecologia. Também, demonstrou como aplicar essas caldas no campo (Figura 4). Para Santos et al. (2014), através da agroecologia é possível a diversificação dos produtos, com baixo custo, aproveitamento e otimização dos insumos, além da sua capacidade de causar menores danos ao ambiente do que a agricultura convencional. 
FIGURA 4. Demonstração da professora Priscila de como produzir caldas para controle de pragas e doenças.

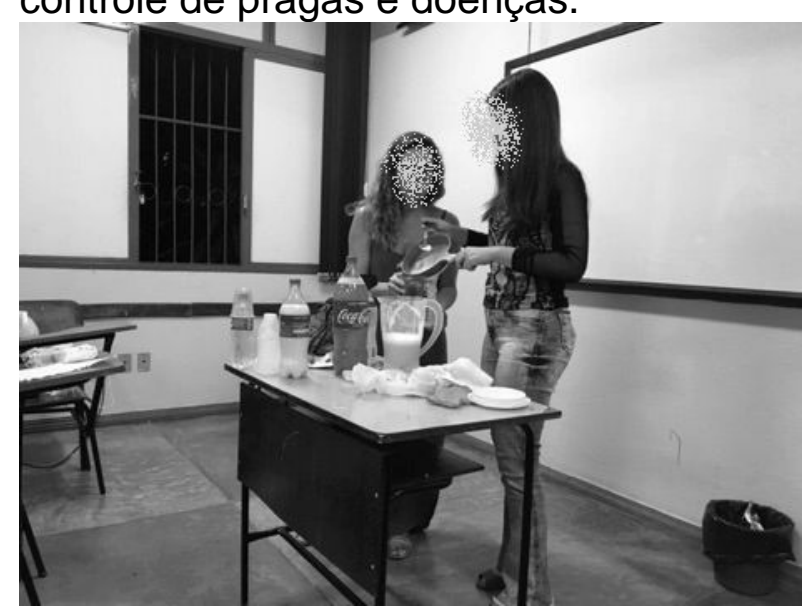

Fonte: As autoras, (2019).

Segundo Santos et al. (2014), através das práticas agroecológicas objetiva-se a permanência das famílias no campo com o manejo sustentável dos solos, a conservação dos recursos naturais, a valorização dos saberes locais e a independência dos agricultores familiares que podem comercializar seus produtos sem a presença do atravessador.

Os participantes relataram em entrevista no final das oficinas, que $90 \%$ reside e possuem residência ou propriedade rural em Ituiutaba. Ainda, após as oficinas, $55 \%$ dos agropecuaristas desejam utilizar os conhecimentos das oficinas para produzir novos produtos ou agregar valor aos seus produtos. Os agropecuaristas acreditam ser possível produzir de acordo com os fundamentos introduzidos pelas oficinas do projeto.

É preciso reafirmar que a agregação de valor é obtida a partir da elevação do preço de um produto em função de seu melhoramento ou transformação, isto é, valor acrescido dentro de várias etapas da cadeia produtiva, podendo ser na agroindustrialização ou na comercialização, seja com embalagem, apresentação especial ou outros (SOUSA; SANTOS, 2015).

Através das oficinas, foi possível fortalecer e ampliar os conhecimentos dos agricultores familiares em torno de processos e tecnologias de transformação da produção, na perspectiva da alimentação familiar e da venda ao mercado consumidor com algum valor agregado.

\section{CONCLUSÕES}

Os agricultores familiares de Ituiutaba-MG demonstraram boa aceitabilidade dos novos produtos. A busca por formas e alternativas viáveis para a manutenção dos agropecuaristas familiares em suas propriedades é condição fundamental para o desenvolvimento socioeconômico destes. Além disso, somente através de medidas racionais de aproveitamento, manejo e uso sustentável do Cerrado é que garantiremos que este não desapareça por completo. Dessa forma, trabalhos dessa natureza devem ser incentivados e reproduzidos em outras regiões dentro do Bioma Cerrado.

Surge, então, a necessidade de considerar ações que possam apoiar a qualificação dos produtos da agricultura familiar às normas sanitárias. Além disso, é necessário também mobilizar amplamente as famílias produtoras, consumidores e 
poder público para um diálogo e propostas sobre os modelos de produção e consumo, e sobre a proteção da produção familiar e dos alimentos seguros no contexto do desenvolvimento local.

O projeto teve seu objetivo central proposto atingido uma vez que era o de transferir tecnologias de processamento e, assim, contribuir com o desenvolvimento socioeconômico dos agricultores familiares da região. A experiência possibilitou, também, o estreitamento das relações dos produtores rurais com a universidade.

\section{REFERÊNCIAS}

ABRAMOVAY, R. Desenvolvimento sustentável: qual a estratégia para o Brasil? Novos estudos, v. 87, p. 97-113, 2010. Disponível em: <https://www.scielo.br/j/nec/a/hfsJ9MWhbhC4MmrkFmYxSJq/abstract/?lang=pt>.

ASSIS, R. L.; ROMEIRO, A. R. Agroecologia e agricultura familiar na região CentroSul do estado do Paraná. Revista de Economia e Sociologia Rural, v. 43, n. 1, p. 155-177, 2005. Disponível em: < https://doi.org/10.1590/S010320032005000100009>. doi: 10.1590/S0103-20032005000100009

CARVALHO, I. S. H. Potenciais e limitações do uso sustentável da biodiversidade do Cerrado: um estudo de caso da Cooperativa Grande Sertão no Norte de Minas. Dissertação de Mestrado. Universidade de Brasília, Brasília, Brasil. 2007. Disponível em: <https://repositorio.unb.br/handle/10482/3442>.

CIRIACO, A. Agregação de valor na cadeia de produtos lácteos para a agricultura familiar em Mato Grosso do Sul: entraves e desafios. Anais do AGROECOL Seminário de Agroecologia da América do Sul, Dourados, 2. Dourados: EMBRAPA - 2016.2 Disponível em: <https://www.cpao.embrapa.br/cds/agroecol2016/PDF's/Mesa\%20Redonda>.

EMATER - Empresa da Assistência Técnica e Extensão Rural do Estado de Minas Gerais Relatório de Atividades. Balanço Social. 2017. Disponível em: <http://www.emater.mg.gov.br/doc/intranet/upload/REL_ATIVIDADE/Balanco\%20Soci al2017.pdf>.

FIGUEIREDO, A. F. R.; FIGUÊIREDO, V. R. Treinamento agroindustrial de pequenos produtores do sul da Bahia. Revista Eletrônica de Extensão, v. 7, n. 10, p. 50-157, 2010. Disponível em: < https://doi.org/10.5007/1807-0221.2010v7n10p150>. doi: 10.5007/1807-0221.2010v7n10p150

FONSECA, R. G.; SANTOS, J. C. A relação cidade-campo no município de Ituiutaba (MG). Horizonte Científico, v. 5, n. 2, p. 1-29, 2011. Disponível em: <http://www.seer.ufu.br/index.php/horizontecientifico/article/view/4428>.

GERMANO, P. M. L.; GERMANO, M. I. S. Higiene e vigilância sanitária de alimentos. Qualidade das matérias-primas, doenças transmitidas por alimentos. Treinamento de Recursos Humanos. São Paulo: Livraria Varela. 2003. 
IBGE - Instituto Brasileiro de Geografia e Estatística. Área dos Municípios. 2018. Disponível em: <https://www.ibge.gov.br/geociencias/todos-os-produtosgeociencias/15761-areas-dos-municipios.html>.

Pesquisa Pecuária Municipal. 2016. Disponível em: <https://www.ibge.gov.br/estatisticas/economicas/9107-producao-da-pecuariamunicipal.html>.

OLIVEIRA, D.; GAZZOLA, M.; SCHNEIDER, S. Produzindo novidades na agricultura familiar: agregação de valor e agroecologia para o desenvolvimento rural. Cadernos de Ciência \& Tecnologia, v. 28, n. 1, p. 17-49, 2011. Disponível em: <http://dx.doi.org/10.35977/0104-1096.cct2011.v28.12034>. doi: 10.35977/01041096.cct2011.v28.12034

OLIVEIRA, H. C. M. Expansão urbana e desigualdades socioespaciais: o exemplo de Ituiutaba (MG). Anais do SIRIRI, TER - Seminário Internacional RIO, Taller de Editores RIER, Salvador, 6. Salvador: UFBA. 2014. Disponível em: <https://www.academia.edu/13807708/Expans\%C3\%A3o_urbana_e_desilgualdades socioespaciais_o_exemplo_de_Ituiutaba_MG_>

PEREIRA, J. O.; BANNWART, T.; MARCOLINO, L.; SIMÕES, C. G. 0 guia do serviço de inspeção municipal de Querência. Mudando para Incluir. Querência: Secretaria Municipal de Indústria, Comércio, Agricultura e Meio Ambiente. 2018. Disponível em: $<$ https://ipam.org.br/wpcontent/uploads/2018/10/GuiadoServic\%CC\%A7oQuere\%CC\%82ncia_web.pdf>.

PINHEIRO, F. A.; CARDOSO, W. S.; CHAVES, K. F.; OLIVEIRA, A. S. B. O.; RIOS, $S$. A. Perfil dos consumidores em relação à qualidade de alimentos e hábitos de compras. UNOPAR Científica - Ciências Biológicas e Saúde, v. 13, n. 2, p. 95102, $2011 . \quad$ Disponível em: <https://journalhealthscience.pgsskroton.com.br/article/view/1231/1181>

SANTOS, C. F.; SIQUEIRA, E. S.; ARAÚJO, T. I.; MAIA, Z. M. G. A agroecologia como perspectiva de sustentabilidade na agricultura familiar. Ambiente \& Sociedade, v. 27, n. 2, p. 33-52, 2014. Disponível em: < https://doi.org/10.1590/S1414-753X2014000200004>. doi: 10.1590/S1414753X2014000200004

SILVA, E. M. S.; PENEIREIRO, F. M.; STRABELI, J.; CARRAZZA, L. R. Guia de elaboração de pequenos projetos socioambientais para organizações de base comunitária. Brasília: Instituto Sociedade, População e natureza. 2014. Disponível em: <https://pt.scribd.com/document/381200338/Guia-de-Elaboracao-de-PequenosProjetos-Socioambientais-para-Organizacoes-de-Base-Comunitaria-2014-pdf>.

SOUTO, T. S.; BEZZI, M. L. As transformações resultantes da cadeia produtiva do leite em Ituiutaba/MG: o produtor leiteiro em foco. Boletim de Geografia, v. 36, n. 1, p. 76-91, 2018. Disponível em: < https://doi.org/10.4025/bolgeogr.v36i1.32979>. doi: 10.4025/bolgeogr.v36i1.32979 
SOUSA, J. B. S.; SANTOS, A. C. Determinação do valor agregado para os frutos do Cerrado: estudo de caso da comunidade Monjolo. Anais do ENEGEP - Encontro Nacional de Engenharia de Produção, Fortaleza, 35. Rio de Janeiro: ABEPRO. 2015. Disponível em: <http://www.abepro.org.br/publicacoes/index.asp?ano=2015>. 